\title{
REVIEW
}

\section{Occupational asthmagens}

\author{
Graeme P. Currie ${ }^{\mathrm{a}}$, Jon G. Ayres ${ }^{\mathrm{b}, *}$
}
a Chest Clinic C, Aberdeen Royal Infirmary, Foresterhill, Aberdeen AB25 2ZN, Scotland, UK
${ }^{b}$ Department of Environmental and Occupational Medicine, Foresterhill Road, Aberdeen AB25 2ZP,
Scotland, UK

Received 8 November 2004; accepted 12 November 2004

\section{KEYWORDS}

Occupational asthma;

Asthmagens;

Reactive airways

dysfunction syndrome
Summary Occupational asthma is caused by exposure to a workplace irritant. It is one of the few subtypes of asthma where a cure can be achieved by removing the cause, or the individual, from the workplace. The agent irnplicited is frequently obvious to the investigating clinician, although aitimes it may remain elusive. This review will discuss the definition of cupational asthma and asthmagens, the working environments gifer which they are cornmonly found, and what should be done on disfecery of an occupation it a.thrigen.

(c) 2004 General Practice Air 1 ays Group. Published by Elsevier Ltd. All rights reserved.

\section{Contents}

What is asthma?

What is occupational asthma? .

What is an asthmagen?

What are the most common occupational asthmagens?

Identifying an asthmagen.

Occupational asthmagens

Low molecular weight asthmagens . .

High molecular weight asthmagens

\footnotetext{
* Corresponding author. Tel.: +44 1224 559456; fax: +44 1226662990

E-mail address: j.g.ayres@abdn.ac.uk (J.G. Ayres).
} 


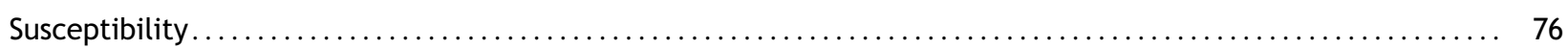

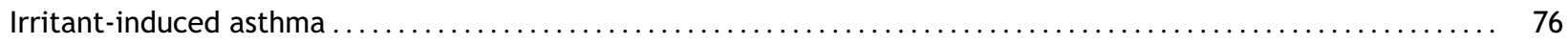

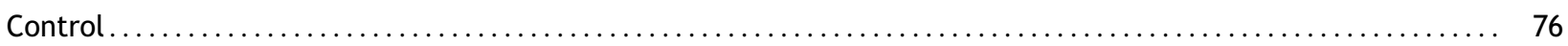

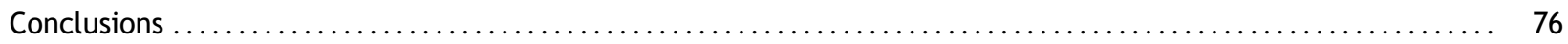

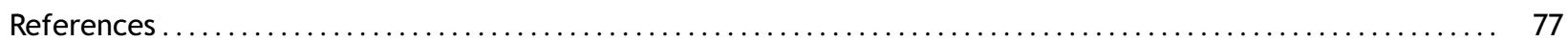

\section{What is asthma?}

Asthma is a heterogeneous common chronic condition characterised by endobronchial inflammation with consequent bronchial hyperresponsiveness [1]. This leads to variable airflow obstruction and typical symptoms such as cough, breathlessness, chest tightness, wheeze and reduced exercise tolerance. The precise aetiology of asthma remains uncertain, but genetic and environmental factors such as viruses, allergen exposure, early use of antibiotics, and numbers of siblings have all been implicated in its inception and development [2]. Once symptoms have developed, treatment is usually indicated and can vary from intermittent use of short acting $\beta_{2}$-agonists to combinations (if

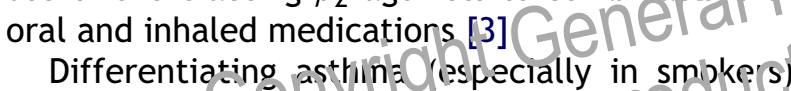
from other airwas diseases, notai) yoctronic obstructive airways disease (CCPD), can be difficult. However, a determined attempt must be made because of treatment and prognostic implications [4], and this is of considerable importance in the occupational setting. It can be argued that particular disease-labelling may delay action in terms of removing an individual with work-related symptoms from exposure to a causal agent. Similarly, individuals with COPD may not necessarily require relocation from a particular occupational environment. At present, the law states that a diagnosis of occupational asthma is required if compensation is to be successful. Thus, despite demonstrating temporally-associated work-related symptoms and variable airflow obstruction, without a documented diagnosis of occupational asthma it is unlikely that a compensation claim would succeed.

\section{What is occupational asthma?}

Occupational asthma may account for as much as $10 \%$ of new cases of adult onset asthma, and a clear association with the work environment is generally a prerequisite to its diagnosis. Symptoms are often less pronounced during holidays or weekends, although patients with persistent disease may not exhibit such clear-cut patterns. Classical occupational asthma is caused by a sensitising reaction in the airways in response to exposure to a specific asthmagen-for example, high molecular weight agents such as proteins in rat urine (in laboratory workers), or low molecular weight agents such as isocyanates (in paint sprayers).

A second form of occupational asthma is termed reactive airways dysfunction syndrome (RADS). This generally occurs as a consequence of a large single exposure to gas, vapour of intir (15) Individuals tend not to have hac iovious espiratory symptoms anc "sonte a uthorities suggest that atopy should not doepresent [6]. Sy'roums classically develop within 24 hours of $\mathrm{Expcsure}$ and non-specific bronchial hiperresponsiveness persists for at least three months [7]. Recently, there has been increasing discussion about whether more persistent, lower dose exposure to chemicals (which would otherwise be regarded as irritants) could lead to the development of asthma; in such instances the term "irritant-induced asthma" has been introduced [8]. This would therefore embrace individuals with classic RADS but the validity of this approach remains uncertain and is not universally agreed.

A third type of occupational airways disease, falling under the general heading of occupational asthma, is the so-called "asthma-like syndrome". This is most frequently found in agricultural sector workers. Symptoms are not necessarily classically asthmatic, but tend to be "asthma-like". Diagnosis can be difficult since both symptoms and investigations do not fulfil an accepted definition of asthma. It tends to be associated with exposure to one or more allergens, sometimes broadly referred to as organic dusts.

\section{What is an asthmagen?}

Asthmagens can be divided into two separate types, namely inducers and inciters. Inducers are 
Table 1 Common agents known to cause asthma in the workplace and associated occupations.

\begin{tabular}{ll}
\hline Agent & Occupation \\
\hline Isocyanates & Paint sprayers \\
Dyes & Textile workers \\
Latex & Health care workers \\
Wooddust & Timber workers \\
Seafoods & Seafood workers \\
Antibiotics & Pharmaceutical industry \\
Flour & Bakers \\
Metals & Welders \\
Enzymes & Pharmaceutical workers \\
Persulphate & Hairdressers \\
\hline
\end{tabular}

substances which, on single or repeated exposure, cause a previously well individual to develop asthma. In contrast, inciters (or triggers) are substances which can cause symptoms in an individual with pre-existing abnormal airway responsiveness. In the workplace these can result in a diagnosis of work-aggravated asthma which is distinct from occupational asthma.

There are a substantial number of substances which can act as inducers, and an even wider range potentially acting as inciters. Common inciters include physical factors (such as cold air), tobicis smoke, viruses and bacteria. It is irnpociant to note that inducers canded act as triggers. This review wilconde) trate on asthmageno (vil ch $\mathrm{Cact}$ as inducers rather than incitel.

\section{What are the most common occupational asthmagens?}

Occupational asthmagens can generally be classified by molecular weight. Low molecular weight ( $<5000$ daltons) asthmagens largely consist of chemicals such as isocyanates, aldehydes, metals, drugs and wood dusts. High molecular weight ( $\geq 5000$ daltons) asthmagens are nearly all proteins; common examples include flour and grain dust, animal proteins (such as those found in rat urine), latex, and enzymes used in the pharmaceutical industry. Currently there are over 400 recognised occupational asthmagens; Table 1 highlights those most commonly implicated in the United Kingdom (UK).

\section{Identifying an asthmagen}

In a typical work setting, identifying an occupational asthmagen tends to be relatively straightforward. The particular agent may be well recognised, and implementing control measures which reduce exposure and prevent further sensitisation of more members of the workforce may be all that is required. However, occupational asthma can sometimes appear to be a problem in a specific workplace but the asthmagen may be difficult to determine with certainty. This should prompt investigation of the workplace. Indeed, most asthmagens can usually be identified from cross-sectional studies, either of specific industrial processes (e.g. bakeries) or of specific workforces (e.g. paint sprayers within a car manufacturing plant). Theoretically, cross-sectional studies are not ideal in identifying a causal association between an exposure and disease. However, when followed by intervention and subsequent improvement in the incidence of occupational asthma, a true causal association can be inferred. The most effective method in the identification of an asthmagen in the workplace is by cohort or case reference studies. These tend to be expensive and time-consuming as they involve monitoring workforces exposed to specific agents over a given period.

Realising that there mav be a ciuster of cases, and different causes of ocrefutional asthma in a particular vibiknlact is not always simple, since ind viduals may have been referred to different physicians vith arparent work-related symptoms. Mofecver, some workers may not appreciate that their symptoms are of sufficient concern to merit medical attention. Surveillance schemes are able to overcome this problem by identifying clusters of occupations in a specific workplace. For example, the SHIELD reporting system developed in the West Midlands permits the identification of particular workers with symptoms [9]. Other surveillance systems, such as the SWORD scheme are useful, although less detailed information is documented [10] - for example, data are collected by means of identification of clusters by postcode rather than by workplace, which limits its ability to identify new causes. However, there is little doubt that increased levels of awareness and reporting of occupational asthma associated with a specific exposure can result in identification of new occupational asthmagens.

\section{Occupational asthmagens}

The most common occupational asthmagens are found characteristically in a limited number of workforces. In the UK, occupational asthma is most commonly found in paint sprayers, bakers, pastry makers, nurses, chemical workers, animal handlers, welders, food processing workers and timber 
workers (see Table 1). There is thus a link between identifying asthmagenic stimuli through a specific agent or through the specific workforce in its own right. Difficulty does arise at times concerning the nature of a putative offending asthmagen. For instance, it is not entirely clear what the causal agent is in welders with occupational asthma, while in the food processing industry identifying the asthmagen will obviously depend upon the food involved.

\section{Low molecular weight asthmagens}

Isocyanates are usually found in industries where paint-spraying is undertaken [10]. Currently, larger car manufacturers have good exposure control systems and sensitisation is relatively uncommon. Less well-regulated and small enterprise paint-spraying facilities are occasionally unable to provide adequate worker protection; it is in these particular situations that airway sensitisation is more likely to occur. Isocyanates are also found in varnishes and a variety of other paints. The commonest form is toluene diisocyanate (TDI) but a number of others (such as hexamethylene diisocyanate $(\mathrm{HDI})$ ) are also capable of sensitising individuals.

Aldehydes are most frecuentla reofesented in reported causes $p$ or fupational asthma as gluteraldehyde, Ope vasi majority or Cased of gluteraldehyde-induced asthma occurs in the National Health Service (NHS), for example in nurses working in endoscopy suites [10]. However, the frequency of recorded new cases has declined remarkably since totally enclosed sterilising systems have been progressively installed throughout UK hospitals.

Colophony is found in the fluxes of some forms of solder [11]. Despite the fact that colophonycontaining solder is used much less nowadays, cases are still occasionally encountered. The causative agent is resin acid found within the solder flux which has been derived from pine resin. Indeed, some patients who are sensitised to colophony are unable to walk through a pine forest without developing symptoms of asthma.

\section{High molecular weight asthmagens}

After isocyanates, flour and enzymes used in bakeries constitute the second most common cause of occupational asthma in the UK and in many other countries [12]. Despite a greater awareness of occupational asthma, exposure to flour in bakeries remains of concern in the UK and other European countries.

Animal protein exposures are largely identified in animal-handling laboratories [13,14]. There can be a significant fall in peak expiratory flow in these workers on days when exposure to rodents has occurred [13]. This in turn highlights the need for the control of aeroallergens in the work environment using personal protective equipment such as air filtering systems.

Latex is a major cause of sensitisation, mostly within the NHS or scientific community where latex gloves and equipment such as catheters are frequently used [15]. Apart from causing troublesome asthma, dermatological sequelae can frequently be encountered. Since the introduction of powder-free gloves to most hospitals, the incidence of latex asthma has dramatically declined. Indeed, some individuals have been able to return to work as a result of an ability to avoid latex exposure. Wood dust remains a problem in wood yards, and for forestry workers and joiners [16] particularly because of hardwoods (e.g. iroko, mahogany, western red cedar) which produce finer dusts and can cause a high rescesto be delivered to the lungs diring exposure.

Cll General, over the last decade there has Deen relatively litecechange in the proportion of indi diduals witn sensitisation due to specific agents, with the exception of a fall in gluteraldehyde and latex-induced asthma.

\section{How do asthmagens "work"?}

Low molecular weight asthmagens do not directly result in production of antibodies [17]. They work by acting as haptens binding on to human proteins and are typically highly reactive compounds. There are certain molecular "structure alerts" which are much more likely to do this. Typical examples include the isocyanate moiety $(-\mathrm{N}=\mathrm{C}=0)$, primary and secondary amines, diacarboxylic acid anhydrides and dialdehydes. These agents may be implicated in paint sprayers, solderers and cleaners, epoxy resin workers and hospital staff, respectively.

High molecular weight asthmagens usually cause the formation of immunoglobulin (Ig) E antibodies, although some generate IgG4 antibodies. The majority tend to be proteins or glycoproteins of animal or vegetable origin. Exposure to the specific agent causes the degranulation of airway inflammatory cells and the release of preformed mediators such as histamine, cysteinyl leukotrienes, prostaglandins, cytokines and interleukins, which in 
turn leads to bronchoconstriction. This is important in the early asthmatic response. In some situations the asthmagen itself possesses intrinsic enzymatic activity - for example, detergents containing alcalase - and as a result of their own enzymatic activity, they may potentiate allergenicity of the molecule itself by disrupting tight junctions between cells. It is of interest that the house dust mite allergen is, in fact, a digestive enzyme from the digestive tract of the house dust mite, and in itself possesses the same enzymatic activity.

\section{Susceptibility}

Understanding what factors are associated with the development of occupational asthma in one specific individual as compared to another remains difficult, but the degree of exposure is a factor [18]. The duration of exposure and the time required before sensitisation can occur is variable, although the majority of cases of occupational asthma occur within two years of initial exposure [19]. Indeed, the duration of exposure tends to be less important in the development of occupational asthma [20]. A solitary high exposure can lead to RADS, but agents such as toluene diisocyariate may also induce classic occunationabastina in addition to RADS [21]: Therte is ofonlevidence that co-exposure to atergens, for instance with bases such as nitiogen dioxide and $0 z$ (i) Can enhance sensitisation or exacerbate existing asthma.

While it is highly likely that genetic factors confer a degree of susceptibility, these are poorly understood at present. Smoking and atopy are clearly risk factors for some forms of occupational asthma [19]. Smoking increases the chance of developing occupational asthma to low molecular weight chemicals (particularly platinum [22]) and, along with atopy, in response to agents which cause IgE production. Smoking is also an independent risk factor in the development of occupational asthma caused by prawns [23], green coffee and caster beans [24], isocyanates [25], salmon [26] and snow crab [27].

\section{Irritant-induced asthma}

This is a much more contentious area since exposures are frequently multiple and at present the list of potential agents which could cause either RADS or irritant-induced asthma is wide. Whilst it is accepted that volatile organic compounds can induce specific IgE production in animals, the exact mechanism in humans is far from clear.
There is currently considerable debate concerning the exact relationship between this condition and classical occupational asthma, and also concerning its optimum treatment.

\section{Control}

In the work setting, the aim of the occupational physician is to identify responsible asthmagens and remove the worker from exposure. In some cases this will depend upon reducing exposure to a level at which sensitisation or the development of asthma is unlikely to occur. It is important to be aware that, in only a very few cases is there sufficient evidence to support a clear threshold level below which sensitisation will not occur. Consequently, the best approach is to remove the exposure completely and find a substitute material to work with. Where this is not possible, personal protective equipment should be provided, such as is needed in animal and pharmaceutical workers. Dealing with exposures can be very effective in individual work places cnd has proven to be very successful in ecuciry the incidence of gluteraldehy def : ric latex-induced asthma.

tlthe pharmacological armamentarium used in conventionlit as way' 'for lastrima caused by occupational exposure [3]. There should be a stepwise management regime incorporating the use of intermittent short acting $\beta_{2}$-agonists and regular inhaled corticosteroids with the possible addition of long acting $\beta_{2}$-agonists.

\section{Conclusions}

Occupational asthma, which is both preventable and treatable, is an important cause of respiratory morbidity in the working environment. It is an important diagnosis to make, in terms of preventing affected individuals becoming chronically exposed to asthmagens, and in deciding upon those who may qualify for compensation. With the persistent introduction of new chemicals and potential sensitising agents it is likely that both the incidence and prevalence of occupational asthma will continue to rise. This suggests that clinicians should maintain a high degree of vigilance when encountering all new cases of adult asthma and should record a full and detailed employment history during initial and subsequent assessment.

\section{Conflicts of interest}

None declared. 


\section{References}

[1] Currie GP, Jackson CM, Lipworth BJ. Does bronchial hyperresponsiveness in asthma matter? J Asthma 2004;41:247-58.

[2] Sandford AJ, Weir TD, Pare PD. Phenotypic heterogeneity in asthma and allergy. Clin Exp Allergy 1998;28(Suppl 1):26-31, discussion 32-26.

[3] British guideline on the management of asthma. Thorax 2003;58(Suppl 1):i1-94.

[4] Chronic obstructive pulmonary disease. National clinical guideline on management of chronic obstructive pulmonary disease in adults in primary and secondary care. Thorax 2004;59(Suppl 1):1-232.

[5] Brooks SM, Weiss MA, Bernstein IL. Reactive airways dysfunction syndrome (RADS). Persistent asthma syndrome after high level irritant exposures. Chest 1985;88:376-84.

[6] Bardana Jr EJ. Occupational asthma and related respiratory disorders. Dis Mon 1995;41:143-99.

[7] Chan-Yeung M. Assessment of asthma in the workplace. ACCP consensus statement. American College of Chest Physicians. Chest 1995;108:1084-117.

[8] Tarlo SM. Workplace irritant exposures: do they produce true occupational asthma? Ann Allergy Asthma Immunol 2003;90:19-23.

[9] Gannon PF, Burge PS. The SHIELD scheme in the West Midlands Region, United Kingdom. Midland Thoracic Society Research Group. Br J Ind Med 1993;50:791-6.

[10] McDonald JC, Keynes HL, Meredith SK. Reported incidence of occupational asthma in the United Kingdom, 1989-97. Occup Environ Med 2000;57:823-9.

[11] Burge PS, Edge G, Hawkins R, White V, Taylor AJ. Occupational asthma in a factory making flux-cored solder corltaining colophony. Thorax 1981;36:828-2-1,

[12] Brisman J, Jarvholm B, Lillienter! L. Ex ocure-response re

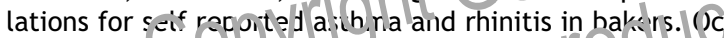
cup Environ Med $2(00 ; 57: 333-40$.

[13] Hollander A, Heederik D, Bruneiree? Lork-related changes in peak expiratory flow among laboratory animal workers. Eur Respir J 1998;11:929-36.

[14] Sjostedt L, Willers S, Orbaek P, Wollmer P. A seven-year follow-up study of lung function and methacholine responsiveness in sensitized and non-sensitized workers handling laboratory animals. J Occup Environ Med 1998;40:11824.
[15] Di Stefano F, Siriruttanapruk S, McCoach J, Di Gioacchino M, Burge PS. Occupational asthma in a highly industrialized region of UK: report from a local surveillance scheme. Allerg Immunol (Paris) 2004;36:56-62.

[16] Schlunssen V, Schaumburg I, Heederik D, Taudorf E, Sigsgaard T. Indices of asthma among atopic and non-atopic woodworkers. Occup Environ Med 2004;61:504-11.

[17] Chan-Yeung M, Malo JL, Tarlo SM, Bernstein L, Gautrin D, Mapp C, et al. Proceedings of the first Jack Pepys Occupational Asthma Symposium. Am J Respir Crit Care Med 2003;167:450-71.

[18] Chan-Yeung M. Occupational asthma. Chest 1990;98: 148S-61S.

[19] Chan-Yeung M, Malo JL. Occupational asthma. N Engl J Med 1995;333:107-12.

[20] Malo JL, Ghezzo H, D’Aquino C, L'Archeveque J, Cartier A, Chan-Yeung M. Natural history of occupational asthma: relevance of type of agent and other factors in the rate of development of symptoms in affected subjects. J Allergy Clin Immunol 1992;90:937-44.

[21] Luo JC, Nelsen KG, Fischbein A. Persistent reactive airway dysfunction syndrome after exposure to toluene diisocyanate. Br J Ind Med 1990;47:239-41.

[22] Venables KM, Dally MB, Nunn AJ, Stevens JF, Stephens R, Farrer $\mathrm{N}$, et al. Smoking and occupational allergy in workers in a platinum refinery. Bmj 1989;299:939-42.

[23] McSharry C, Anderson K, McKay IC, Colloff MJ, Feyerabend $C$, Wilson RB, et al. The IgE and IgG antibody responses to aerosols of Nephrops norvegicis $(\mathrm{crd} \sqrt{ }$ (n) antigens: the association with clinical hyer ser sitivity and with cigarette smoking. C'ii) Exp rirnu ol 1994;97:499-504.

24] F C M ino C, Sulotto F, Piolatto G, Ciacco C, Capellaro E, Falagrani P, et aL Ficcors related to the development of sensitizacion t, gi $\in \in$ Cotfee and castor bean allergens among Cfliet workers. Clin Exp Allergy 1995;25:643-50.

[25] Meredith SK, Bugler J, Clark RL. Isocyanate exposure and occupational asthma: a case-referent study. Occup Environ Med 2000;57:830-6.

[26] Douglas JD, McSharry C, Blaikie L, Morrow T, Miles S, Franklin D. Occupational asthma caused by automated salmon processing. Lancet 1995;346:737-40.

[27] Cartier A, Malo JL, Forest F, Lafrance M, Pineau L, St-Aubin $\mathrm{JJ}$, et al. Occupational asthma in snow crab-processing workers. J Allergy Clin Immunol 1984;74:261-9.

Available online at www.sciencedirect.com

science@irect 